\title{
Innovation and Optimal Punishment, with Antitrust Applications
}

\author{
Keith N. Hylton* \\ Haizhin Lin ${ }^{* *}$
}

Abstract: This paper modifies the optimal penalty analysis by incorporating investment incentives with external benefits. In the models examined, the recommendation that the optimal penalty should internalize the marginal social harm is no longer valid as a general rule. We focus on antitrust applications. In light of the benefits from innovation, the optimal policy will punish monopolizing firms more leniently than suggested in the standard static model. It may be optimal not to punish the monopolizing firm at all, or to reward the firm rather than punish it. We examine the precise balance between penalty and reward in the optimal punishment scheme.

Keywords: optimal law enforcement, optimal antitrust penalty, monopolization, innovation, internalization, strict liability, static penalty.

JEL Classification: D42, K14, K21, K42, L41, L43

\footnotetext{
${ }^{*}$ Honorable Paul J. Liacos Professor of Law, Boston University.

${ }^{* *}$ Assistant Professor, Kelley School of Business, Indiana University.
} 


\section{Introduction}

Strict liability rules are rare in the law. In general, legal rules apply a rough cost-benefit test to determine liability - the negligence rule of torts is the most common example. Indeed, it would be a fair summary to say that courts attempt to exempt efficient conduct from punishment, through the use of cost-benefit legal tests, and apply general statutorily-determined penalties to the conduct that violates the law. For example, in American antitrust law, courts use rule of reason analysis to exempt efficient conduct for the most part, while applying statutorily-set penalties or treble damages to the violations.

This basic pattern in the law makes it difficult to apply the lessons from the economic theory of punishment. The literature offers models in which offenders are held strictly liable for their offenses and assessed with case-specific optimal penalties (depending on the harm and probability of punishment in the particular case). The law, in contrast, applies a case-specific cost-benefit analysis to the determination of liability, and then uses standard off-the-rack penalties (statutory penalties, compensatory damages, or predetermined damage multipliers).

In spite of this difference between the theory of punishment and the practice in courts, the theory remains useful as a guide for policy. This paper will follow the tradition of the optimal punishment literature by examining optimal penalties as a source of guidelines for legal policy. The specific focus here is innovation and punishment, especially in the context of antitrust and products liability.

The prevailing analysis of optimal antitrust penalties holds that in order to avoid overdeterring efficient conduct, the optimal penalty would internalize the social losses generated by the offensive conduct (Becker, 1968, at 199). If enforcement is perfect and costless, such a 
penalty would internalize the transfer from consumers and the deadweight loss (Landes, 1983). Thus, if the monopolizing firm introduced efficiencies, it might still have an incentive to carry out its monopolizing conduct, as long as the value of the efficiency gain exceeded the deadweight loss.

This analysis is incomplete because it is based on a model that does not incorporate some plausible social benefits from monopolizing activity. The prevailing analysis employs a "static model" in which the gains from monopolization accrue to the firm and the losses are suffered by society. In contrast, a "dynamic model" would more likely take into account the social gains from investments made by the firm in its effort to become a monopoly. Investments in marketcreating or market-expanding innovation should be incorporated into the economic analysis of punishment.

This paper modifies the optimal penalty analysis by explicitly incorporating dynamic incentives with external benefits. In the models examined, the recommendation that the optimal antitrust penalty should seek to internalize the marginal social harm, as measured by consumer transfer and the deadweight loss (the static penalty), is no longer valid as a general rule. We explore the precise recommendations from two simple versions of the "dynamic model", one in which the offender (firm) invests in market-expanding innovation, and another in which victims invest.

We focus on antitrust applications, although the model can be applied to patent law, tort law, and other areas. The most important implication is that in light of the benefits from innovation, the optimal policy will punish monopolizing firms more leniently than suggested in the standard static model. It may be optimal to not to punish the monopolizing firm at all, or to reward the firm rather than punish it. In this sense, this paper provides a Schumpterian approach 
to punishment, ${ }^{1}$ as well as the groundwork for a positive account of monopolization law, which has been puzzlingly lenient over its history. ${ }^{2}$

In general, the optimal penalty for monopolization is a function of the consumer harm, the residual consumer surplus after monopolization, and the relative responsiveness of innovation and monopolization to changes in the penalty. Indeed, the optimal penalty turns out to be a weighted average of the static penalty and an innovation subsidy, with the weights determined by the relative sensitivities of investment and of monopolization to punishment.

Although the focus here is antitrust, we discuss other applications. The models can be applied easily to torts. The connection between innovation and punishment is of great concern in both the antitrust and products liability settings. In U.S. v. Microsoft, ${ }^{3}$ the D.C. Circuit Court of Appeals refused to apply a per se liability rule to the firm's technological integration of the internet browser and operating systems largely because of its concern that such a rule would discourage innovation. ${ }^{4}$ In Trinko v. Verizon, ${ }^{5}$ the U.S. Supreme Court cited the negative innovation effect as one basis for refusing to adopt the "essential facilities" theory of liability for monopolization. ${ }^{6}$ Products liability lawsuits against drug manufacturers have been met with the criticism that their success will deter the development and marketing of new beneficial drugs. ${ }^{7}$ The difficult and relatively unexplored issue in these cases is determining the precise relationship

\footnotetext{
${ }^{1}$ Schumpeter (1943) (Chapters 7 and 8) famously criticized static model of competition for ignoring the social benefits of innovation, and the need for firms to gain monopoly power in order to earn a positive return on socially valuable innovation. For a review, see Mason (1951). This paper offers a simple model that incorporates innovation and examines the optimal antitrust penalty.

${ }^{2}$ On the perceived leniency of monopolization law and its explanation, see Evans and Hylton (2008).

3253 F.3d 34 (D.C. Cir. 2001).

${ }^{4} \mathrm{Id}$. at 89-90. In addition, much of the commentary about the Microsoft litigation focused on the implications of antitrust enforcement for innovation in the technology industries, see Evans and Schmalensee (2002).

${ }^{5} 540$ U.S. 398 (2004).

${ }^{6} \mathrm{Id}$. at 407.

${ }^{7}$ See, e.g., Steven Shavell and A. Mitchell Polinsky, Op-Ed, Vioxx Verdict's Dark Side, Boston Globe, Aug. 23, 2005, at A15, available at http://www.boston.com/news/globe/editorial_opinion/oped/articles/2005/08/23/vioxx_verdicts_dark_side/.
} 
between the deterrence of offensive conduct and the encouragement of innovation in an optimal punishment scheme.

Parts II.A and II.B set up the basic or "static" version of the model explored in this paper. The model replicates the standard optimal punishment recommendation, which is then applied to antitrust. Parts II.C.2 and II.C.3 explore punishment in a setting in which the offender makes an investment that provides social benefits, the returns to which are a function of an offense that he may commit in the future as well as the punishment for that offense. Part II.C.4 examines the case in which the victims make investments, the expected returns to which are reduced by an offense that may be committed by the offender. Part III discusses the implications of these models for the law.

\section{Model}

\section{A. Basic Assumptions}

We assume all actors are risk neutral and victims are the only parties who suffer loss. The state attempts to apprehend an offender only after an injury has occurred. The state is successful in each attempt to apprehend an offender. However, the state does not attempt to apprehend the offender in each instance of an offense, and therefore the probability of apprehension given an injury is less than one. Once apprehended punishment is certain.

The following variables will be used throughout the analysis. Let $z=$ probability of apprehension. We assume that there is a lower limit $z^{\prime}$ on the feasible values of $z$, so that $0<z^{\prime}$ $<z \leq 1$. Let $c=$ the cost to the state of apprehending the offender, $c>0 ; v=$ the loss suffered by a victim, $v>0 ; F=$ fine imposed on apprehended offender; $M=$ the gross gain to the offender from committing an offense, $M>0$. 
We assume $M$ is governed by the probability distribution function $H$ with corresponding density function $h$, where $h(M)>0$ for $0<M<M_{u}$, and $h(M)=0$ otherwise. The offender will commit the offense if $M>z F$; therefore the probability that the offender does not commit an offense is $H(z F)$. If $M_{u} \leq z F$ no crimes will be committed (the offender will not commit an offense when he is indifferent). Thus, $F=M_{u} / z$ is the minimum level of the fine that achieves complete deterrence.

We assume the offender cannot satisfy his preferences through the market; thus in order to enjoy the gain $M$ he must commit an offense. The time line of events is as follows: the offense occurs with probability $1-H(z F)$ causing a loss of $v$; enforcement occurs with probability $z$; the offender is apprehended at $\cos t c$, and then punished with a fine equal to $F$.

B. Optimal Punishment Policy: Static Case

The optimal punishment policy is the combination of the fine and the probability of apprehension that minimizes the cost of offenses and the cost of avoiding offenses:

$$
C=(1-H(z F))(v+z c)+H(z F) E[M \mid M<z F] .
$$

There are, of course, alternative formulations of the social welfare function that yield the optimal policy. An equivalent objective is to choose $z$ and $F$ to maximize the net benefit from offenses $N B$ (offenses) $=(1-H(z F)) E[M-v-z c \mid M>z F]$. Alternatively, one could maximize the difference between net deterrence benefits and the costs of enforcement $H(z F))(v-E[M \mid M<z F])-(1-$ $H(z F)) z c$. The results are the same under these specifications. The optimal policy can be stated as follows. 
Proposition 1: If $M_{u}>v+z^{\prime} c$, then the optimal punishment policy is to set the fine so that it satisfies $F=F^{*}=v / z^{\prime}+c$, and the probability of apprehension at the minimum level $z^{\prime}$. If $M_{u} \leq v+z^{\prime} c$, then the optimal policy is to set the fine and probability of apprehension so that $z F$ $\geq M_{u}$ (complete deterrence rule).

This proposition is a familiar result that replicates that of Becker (1968), and also Polinsky and Shavell (1992) with minor modifications. We provide proofs in the appendix. The intuition behind it is that if the offensive activity is potentially efficient, in the sense that the gain to some offenders exceeds the marginal social cost of the activity, then the optimal penalty internalizes the social cost of the offender's conduct. In order to minimize the costs of enforcement, the state sets the probability of apprehension at its minimum level. However, if the criminal activity is not potentially efficient, the optimal policy aims to completely deter it. As Becker noted, the internalizing penalty $F^{*}$ satisfies the complete deterrence goal in cases in which the offensive activity is not potentially efficient.

The antitrust application for this basic model is straightforward. ${ }^{8}$ First, an antitrust punishment authority should distinguish between acts that are potentially efficient and acts that are not potentially efficient. Conduct with substantial efficiency justifications, such as product tying, would be subjected to the internalization rule. Conduct without efficiency justifications, such as naked price fixing, would be subjected to the complete deterrence rule. Thus, in a naked price fixing case the goal of punishment would be to impose a penalty that wipes out the gains from price fixing. Of course, this goal would be satisfied by the internalization rule penalty $F^{*}$, but many other penalty levels will also satisfy this goal.

\footnotetext{
${ }^{8}$ Punishment in this model occurs through action of an enforcement authority that imposes a discrete fine after the monopolizing act occurs. We do not allow in this model for victims to sue for damages, which could complicate matters in the antitrust context, see Baker (1988).
} 
In the static case examined here the monopolizing firm takes an act that allows it to extract consumer surplus from consumers. That act may also generate an efficiency gain that benefits the firm, as shown in Figure 1. For example, the monopolizing act might be an exclusive dealing contract that both forecloses competition and reduces supply costs. The firm's gross gain from its conduct is equal to the sum of the transfer and efficiency gain $(M=T+E)$. The social cost is the sum of the transfer and deadweight loss components (i.e., $v=T+D$ ). The optimal antitrust penalty is therefore $F^{*}=(T+D) / z^{\prime}+c$. If no efficiency gain were possible $(E=0)$ in connection to the firm's conduct, as in the example of naked price fixing, the optimal policy would set the penalty so that it eliminates the gains from monopolization $\left(F \geq T / z^{\prime}\right)$. The penalty $F^{*}$ would serve this purpose, as would any other penalty greater than $T / z^{\prime}$. 


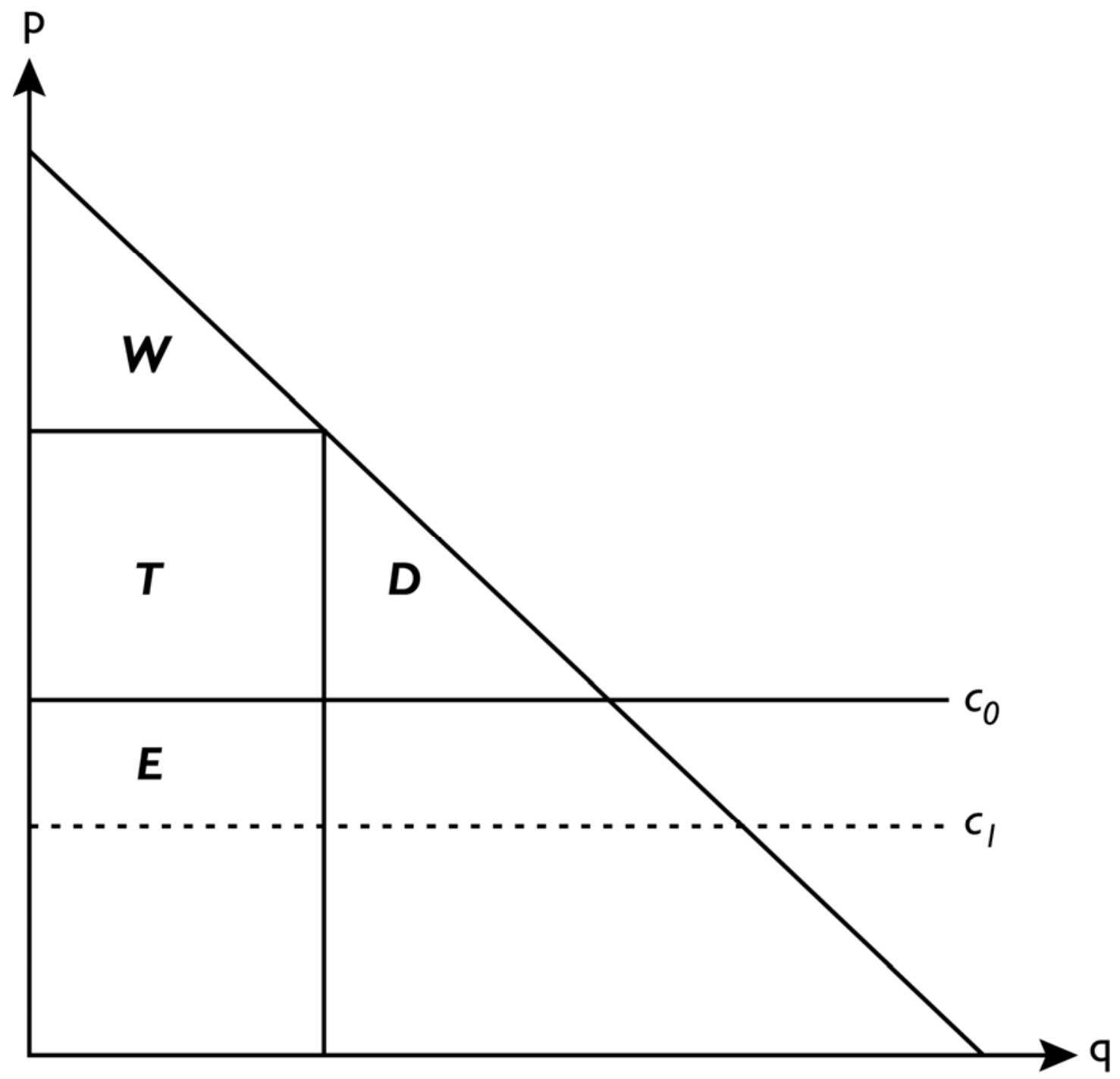

Figure 1 
C. Optimal Punishment Policy in a Dynamic Setting

In the previous part we examined the static enforcement model in the context of antitrust, replicating the static (Becker-Landes) punishment rule (internalize the monopoly transfer and deadweight loss). In this part, we extend the enforcement model to incorporate investment by the offender.

The reason for taking investment by the offender into account is that it is an important concern in the antitrust setting, especially in monopolization cases. Suppose the monopolizing firm has undertaken investments that benefit consumers, such as creating a new product market. The static enforcement policy may be socially excessive because it might prevent the firm from earning a break-even return on its investments in the creation of the product market. This is distinguishable from the "static case" examined earlier, where the product market was already in existence and the monopolizing firm took an action that permitted it to gain monopoly power (perhaps also with an efficiency gain). In the dynamic model considered here, the monopolizing firm creates the market and then monopolizes it.

\section{Assumptions}

Using Figure 1, the monopolizing firm invests in the first period creating the market. In the second period, the firm takes an action that monopolizes the market. As in the previous model, the second period action could generate an efficiency gain $(E)$. When the monopolizing firm creates the market, it generates $S=T+D+W$. If the firm is deterred from monopolization, consumers get $S$. If the firm is not deterred from monopolization, consumers get $W$. 
Consider an example. Suppose in the first period the firm invests in the design and production of a new artificial tooth that will be ready to market in the second period. The tooth design can be copied by rivals easily, so the second period market has the potential to be perfectly competitive. However, the firm can reduce competitive pressure by engaging in some exclusionary act at the start of the second period. The ideal exclusionary act would be the attainment of a legal barrier to entry, such as a patent, but suppose such options are not available to the firm. Suppose the firm's best option for excluding competition is entering into an exclusive dealing contract with a key resource supplier, ${ }^{9}$ and that in addition to excluding competition the contract reduces supply costs by permitting the resource supplier to better predict demand. ${ }^{10}$ The returns from the creation of the new artificial tooth depend on the firm's later success in excluding competition. ${ }^{11}$ It will have an incentive to monopolize if the gains from monopolization exceed expected antitrust penalties.

In the remainder of this paper, we will focus on the optimality condition for the penalty. Becker's suggestion that the probability of enforcement should be set at its minimum level (under reasonable assumptions) has not been disturbed in the subsequent literature (e.g., Polinsky

\footnotetext{
${ }^{9}$ This hypothetical is based partly on the facts of U.S. v. Dentsply Intn'l, Inc., 399 F.3d 181 (3rd Cir. 2005). In Dentsply the exclusive dealing contract was with dealers rather than suppliers. An example involving an exclusivity contract with a key supplier was Alcoa's contract to purchase electricity on the condition that the seller refrain from selling electric power to any other producer of aluminum. U.S. v. Aluminum Co. of America (Alcoa), 148 F.2d 416, 422 (2d.Cir. 1945).

${ }^{10}$ For example, the tying contract in International Salt Co. v. United States, 298 U.S. 131 (1936) was explained by Peterman (1979) as a device that permitted the company to better predict, and thereby take advantage of economies in, the distribution of salt.

${ }^{11}$ This story takes the innovation concept as given to the innovator and examines the incentive to carry it out. This is distinguishable from the innovation race in which many firms are attempting to develop a new technology at the same time, in which case perpetual rivalry might, or might not, enhance innovation. See Loury (1979); Lee and Wilde (1980); Aghion, Bloom, Blundell, Griffith, and Howitt (2005). In general, one can distinguish the incentive to search for innovations and the incentive to carry a particular innovation concept out. Competition may reduce the incentive to carry out a particular concept and increase the incentive to search for an innovation.
} 
and Shavell, 1992), ${ }^{12}$ so there is no need to reexamine this question. We will assume, in parts of the discussion, that the optimal policy will set the enforcement probability at the minimum level.

\section{Optimal Punishment: Offender Investment Case}

The potential offender invests in the first period, at cost $k_{o}$. The private return to the offender is determined by his prospects for monopolization. Thus, the potential offender will invest if the expected return from monopolization, net of the penalty, exceeds his investment cost. Let the investment cost $k_{o}$ be governed by the probability distribution $\Psi$ with corresponding density $\psi$. The potential offender invests when $k_{o}<\bar{k}_{o}=(1-H(z F))[E(M \mid M>$ $z F)-z F]$. The probability of investment is therefore $\Psi\left(\bar{k}_{o}\right)$.

The problem for the social planner is to choose the optimal fine to maximize the net social benefit:

$$
\begin{aligned}
N B=\Psi\left(\bar{k}_{o}\right)\left\{\left[(1-H(z F)) E\left(M \mid M>_{z} F\right)-\right.\right. & \left.E\left(k_{o} \mid k_{o}<\bar{k}_{o}\right)\right] \\
& +(1-H(z F))(S-v-z c)+H(z F) S\}
\end{aligned}
$$

where the first term (in brackets) represents the net gain from investment to the would-be monopolist, the second term represents the net gain to society if investment is followed by monopolization $(S-v=S-T-D=W)$, and the third term represents the net gain to society if

\footnotetext{
${ }^{12}$ If there is a fixed cost involved in setting the probability of apprehension, the optimal probability of apprehension may be positive for sufficiently small values of the marginal enforcement cost (Polinsky and Shavell, 1992). Also, if there is a fixed upper limit on the fine, the optimal probability of apprehension will not necessarily be at the minimum level. These are variations on the Becker model that we are not exploring here.
} 
investment is not followed by monopolization. The first order condition with respect to the fine is

$$
\begin{aligned}
\frac{\partial N B}{\partial F}=(v+z c-S-z F)\left\{\Psi\left(\bar{k}_{o}\right) h(z F)+\psi\left(\bar{k}_{o}\right)(1-H(z F))^{2}\right\} \\
-S\left\{\psi\left(\bar{k}_{o}\right) H(z F)(1-H(z F))-\Psi\left(\bar{k}_{o}\right) h(z F)\right\}=0
\end{aligned}
$$

Using this first-order condition, the optimal level of fine satisfies

$$
F^{*}=\frac{v}{z}+c-\frac{S}{z}+\frac{S}{z}\left(\frac{\Psi\left(\bar{k}_{o}^{*}\right) h\left(z F^{*}\right)-\psi\left(\bar{k}_{o}^{*}\right) H\left(z F^{*}\right)\left(1-H\left(z F^{*}\right)\right)}{\Psi\left(\bar{k}_{o}^{*}\right) h\left(z F^{*}\right)+\psi\left(\bar{k}_{o}^{*}\right)\left(1-H\left(z F^{*}\right)\right)^{2}}\right)
$$

The first two terms in (4) are the familiar static (Becker-Landes) penalty, which internalizes the consumer harm. The remaining terms involve penalties or subsidies for the offender's conduct. First, the offender gets a subsidy of $S / z$ in recognition of the potential surplus it delivers to consumers when its investment creates a new product market. This subsidy is divided by the probability of apprehension because the offender gets no subsidy from the state in cases in which it is not punished. The last term in (4) reflects the "dynamic" component of the penalty - the part that is concerned with the investment incentive - and it is a combination of subsidy and penalty. The first component of the numerator reflects a penalty to discourage monopolization; the second is a subsidy to encourage investment. The entire last term can be positive (a penalty) or negative (a subsidy) depending on the responsiveness of investment efforts or of monopolization efforts to the penalty. If investment efforts are more responsive to changes in 
the penalty than are monopolization efforts $(\Psi h-\psi H(1-H)<0)$, the final term in will be a subsidy.

Overall, however, the subsidy effect dominates in the last two terms of (4). Simplifying (4), we have

$$
F^{*}=\frac{v}{z}+c-\frac{S}{z}\left(\frac{\psi\left(\bar{k}_{o}^{*}\right)\left(1-H\left(z F^{*}\right)\right)}{\Psi\left(\bar{k}_{o}^{*}\right) h\left(z F^{*}\right)+\psi\left(\bar{k}_{o}^{*}\right)\left(1-H\left(z F^{*}\right)\right)^{2}}\right)
$$

and the optimal policy can be stated as follows.

Proposition 2: The optimal policy is to set the fine so that it satisfies (5) and the probability of enforcement at the minimum level.

Unlike the static case examined in the previous section, the "complete deterrence rule" setting the fine greater than or equal to the monopolist's gain is no longer a sensible policy. The reason is that where the prospective monopolist's investments make the product market available, its conduct always provides some benefit to society. And since there is always some social benefit from the prospective monopolist's investment, it does not make sense to wipe out its entire gain. This is different from the static case, where the monopolist merely transfers wealth from consumers to itself, and in which a policy of wiping out the monopolist's gains could be optimal.

Let the final term in (5) be represented as $(S / z) \theta$. The optimal penalty is therefore $F=$ $v / z-(S / z) \theta+c$. Moreover, $\theta$ is a discontinuous function of $F$ with the properties $\theta>0 ; \theta=1$ for 
$F \leq 0$; and $\theta^{\prime}(F)<0$ for $F>0$. The properties of the optimal penalty solution are considered in detail in the appendix. ${ }^{13}$

Since $\theta>0$, the optimal penalty is unambiguously less than the static penalty $v / z+c$. In other words, the optimal penalty for monopolization in the innovation setting is unambiguously less than the static penalty that internalizes the consumer harm.

The parameter $\theta$ captures the relative sensitivities of the marginal firm's innovationinvestment and monopolization decisions to the penalty. When

$$
\frac{h\left(z F^{*}\right)}{1-H\left(z F^{*}\right)}>\frac{\psi\left(\bar{k}_{o}^{*}\right) H\left(z F^{*}\right)}{\Psi\left(\bar{k}_{o}^{*}\right)}
$$

we have $\theta<1$. This is the case in which the monopolization incentive exceeds the investment incentive at the margin. The penalty is larger because its shadow price, discouragement of innovation, is relatively low. When the inequality in (6) is reversed (shadow price of investment is high), we have $\theta>1$; and when there is a strict equality we have $\theta=1$. The incentive parameter $\theta>0$, because $\theta=0$ implies complete deterrence, which is ruled out here because it is always desirable for society to enjoy some of the surplus $S$ rather than none of it. ${ }^{14}$

Although the optimal penalty is unambiguously less than the static penalty, it can also be a subsidy given that $\theta$ can take the value of 1 . We explore its precise form in the appendix (under Proposition 2). When the marginal harm $(v z+c)$ exceeds the surplus $S$, the optimal penalty is always positive; i.e., $F^{*}=v / z-(S / z) \theta^{*}+c>0$. This makes sense because it is

\footnotetext{
${ }^{13}$ See Proof of Proposition 2. In this formulation, the net marginal social harm from the offender's conduct consists of the difference between the harm to consumers and the marginal innovation benefit, where the innovation benefit is a function of the size of the penalty.

${ }^{14}$ See Proof of Proposition 2 in the appendix.
} 
desirable to discourage the firm's conduct, though the discouragement is not as severe as in the static case examined earlier. When the marginal harm is less than the surplus, the optimal penalty can be either a penalty or the subsidy $F^{*}=v / z-S / z+c<0$. The choice between penalty and subsidy depends on whether the extra surplus gained from deterring monopolization is greater than the wealth generated from investment.

Substituting the terms from Figure 1, the optimal penalty can be expressed as $F=$ $((T+D) / z)(1-\theta)-(W / z)(\theta)+c$. In this formulation, the optimal penalty is a weighted average of the static monopolization penalty $(T+D) / z$ and an investment subsidy $-W / z$, where the weight is determined by the investment incentive parameter $\theta$. The optimal rule penalizes the firm for a portion of the consumer harm and rewards the firm for a portion of the residual surplus. As the relative investment sensitivity parameter increases the optimal penalty puts more weight on the subsidy component.

Optimal punishment depends largely on the residual surplus $(W)$, the consumer harm $(T+D)$, and the incentive parameter $\theta$. Punishment becomes more severe, holding other factors the same, as the ratio consumer harm to the residual surplus increases. Punishment becomes more severe, again holding other factors the same, as the relative sensitivity of innovation to the penalty falls ( $\theta$ approaches 0$).^{15}$

The most obvious policy implication is that it may not be optimal to punish the firm for monopolization at all, even when there are no efficiencies directly connected to the firm's monopolizing conduct. Consider, for example, the exclusive dealing contract example. If the

\footnotetext{
${ }^{15}$ Baker (2005) argues that antitrust enforcers target their prosecution decisions to cases in which the penalty is more likely to reduce monopolization efforts than to reduce investment efforts. If true, real enforcement could be consistent with the model of this paper. However, this paper's model suggests that there should be no enforcement when the investment elasticity is greater than or equal to the monopolization elasticity. This suggests that a bit more caution or forbearance on the part of enforcement agents may be optimal.
} 
exclusivity contract offers no cost advantage whatsoever, and serves the sole purpose of excluding competitors, it still may not be optimal to impose a penalty on the monopolizing firm. The optimal fine for monopolization could be zero or negative. The reason is that the firm always provides a social benefit through innovation. When it later monopolizes the market, consumers still pocket the residual consumer surplus. One purpose of the fine in this setting is to align private and social incentives for investment. If the private monopolization gain, absent a penalty, is less than the social gain from investment, the optimal policy will include a subsidy. For example, suppose the innovating firm monopolizes the market in the second period with probability one. The social gain from the firm's first-period investment would be the sum of the residual consumer surplus and the monopoly transfer $(W+T)$. The private gain, however, would be equal to the monopoly transfer. The optimal punishment policy trades off deterrence of monopolization with equalizing the private and social gains from investment, and the latter policy requires a bounty based on the residual surplus.

If the potential surplus is equal to zero the optimal penalty obviously simplifies to the static penalty examined earlier. Since the monopolist has invested, one might ask why the optimal penalty would fail to provide some encouragement to investment? Where there is not new surplus anticipated from the firm's investment, the entire investment effort is devoted to transferring surplus from consumers. The monopolist's investments are equivalent to those made in one period by a thief solely to facilitate theft in a later period.

Although we have focused on monopolizing conduct that might fall afoul of the antitrust laws, the model examined here applies equally to the case of a patent. The optimal penalty result provides the optimal "price" that should be charged to a patentee. The relevant ratio that should 
be considered in analyzing patent-antitrust disputes is that between the consumer harm and the residual surplus created by the firm. ${ }^{16}$

\section{Some General Applications of Offender Investment Model}

The offender investment model can be applied to non-antitrust as well as antitrust settings. Consider product safety regulation. The firm invests in the first period, creating the market. In the second period, it decides whether to take care to avoid harming the consumer. It takes care only if the cost of taking care $M$ is less than the expected fine $z F$. The firm's investment in the first period is a function of its profit in the second, which is determined in part by the relationship between $M$ and $z F$. It should be clear that this example is analogous to the innovation-monopolization problem studied in the previous part. The optimal penalty is therefore of the form $F=v / z-(S / z) \theta+c$, where $v$ is the injury to the consumer and $S$ is the surplus from innovation. The incentive parameter $\theta$ captures the relative sensitivities of precaution and innovation, and increases as the shadow price of innovation increases. This is not a weighted average of consumer welfare components (as in the monopolization case) because $v$ does not have any necessary relationship to $S$. The optimal product safety (or liability) fine is unambiguously less than the one that internalizes the consumer injury, and it may be a reward.

Suppose, instead of a strict liability rule, the punishment authority operates under a negligence standard which imposes punishment only when $M<v$. This case has not been

\footnotetext{
${ }^{16}$ On ratio tests and the patent-antitrust cases, see Kaplow (1984). The model here suggests a different type of ratio test than the one recommended by Kaplow. Kaplow focuses on the ratio of the monopolist's reward $(T)$ to the deadweight loss. The relevant ratio suggested in this analysis is that of the residual surplus to the sum of lost and transferred surplus $(T+D)$. One question worth pursuing is whether the case law is more consistent with the ratio test suggested here or Kaplow's ratio test.
} 
considered in the economic treatments of punishment (Becker, 1968; Polinsky and Shavell, 1992), but it would not have made a significant difference in those analyses. Even under a negligence rule, the optimal fine would still internalize the social costs of the offender's conduct. Interestingly, a negligence rule would enable the enforcement authority to avoid any enforcement expenditure at all. The offenders for whom $M>v$ would not be deterred by the threat of punishment (because they are exempted under the negligence rule), and those for whom $M<v$ would be deterred. There would never be a need for enforcers to act. In the standard punishment analysis, exemplified by the static model examined earlier in this paper, negligence is superior to strict liability because it avoids expenditures on apprehension and punishment.

In the innovation context examined here, where the offender's conduct generates a positive externality, the use of a negligence rather than strict liability standard does alter the result for the optimal penalty. If the punishment authority operates under a negligence rule, under which the fine is imposed only when $M<v$, the social objective would be to set the fine to maximize

$$
\begin{aligned}
N B=\Psi\left(\bar{k}_{o}\right)\left\{(1-H(v)) E(M \mid M>v)+\left[(H(v)-H(z F)) E(M \mid v>M>z F)-E\left(k_{o} \mid k_{o}<\bar{k}_{o}\right)\right]\right. \\
+(1-H(z F))(S-v-z c)+H(z F) S\}
\end{aligned}
$$

where $\bar{k}_{o}=(1-H(v)) E(M \mid M>v)+(H(v)-H(z F))[E(M \mid v>M>z F)-z F]$. This objective function reflects the fact that when $M>v$, the punishment authority will apprehend but not punish the offender; when $v>M>z F$, the offender will be punished but will not be deterred from the 
offense; and when $z F>M$, the offender will be deterred from committing the offense. The optimal fine for the negligence case satisfies

$$
z F^{*}=v+z c-\frac{\psi\left(\bar{k}_{o}^{*}\right)\left(H(v)-H\left(z F^{*}\right)\right)(S-(1-H(v))(v+z c))}{\psi\left(\bar{k}_{o}^{*}\right)\left(H(v)-H\left(z F^{*}\right)\right)^{2}+\Psi\left(\bar{k}_{o}^{*}\right) h\left(z F^{*}\right)},
$$

which is smaller than the static expected penalty $(v+z c)$ when the surplus is sufficiently large relative to the marginal social harm from the offense. When the surplus is small relative to the marginal social harm, the optimal penalty exceeds the static penalty. In effect, the optimal penalty under the negligence rule inflates the static penalty and offers a subsidy as well. The reason for inflating the static penalty is to discourage some investment, given that a large share of offenders will not be punished under the negligence rule, even though they have forced society to bear the enforcement costs of apprehending them. ${ }^{17}$ The optimal penalty under the negligence standard is probably (though not necessarily) larger than the optimal penalty under the strict liability standard (5). The subsidy provided by the optimal penalty is smaller because the negligence rule already exempts some potential offenders from any punishment. The static penalty comes closer to being socially optimal (provided a positive penalty is optimal) when the regulator punishes according to the negligence standard.

\section{Optimal Punishment: Victim Investment Case}

\footnotetext{
${ }^{17}$ Indeed, if the surplus is zero, the optimal penalty in (8) is greater than the static penalty. The reason, again, is to discourage investment that yields no social surplus, but generates enforcement (litigation) costs from enforcement efforts.
} 
Now potential victims invest in some activity, at cost $k_{v}$. The gross gain from investment to the potential victim, if there is no offense, is $B$. However, because of the risk that an offense will destroy the value of the investment, the potential victim's expected gain from investment is [1-prob(offense) $] B$. Assume the victim suffers a direct loss $v$ in the event an offense occurs. We will allow $v$ to differ from $B$ because it is possible that the offense both destroys the value of the victim's investment and imposes a different direct loss on the victim.

Returning to the terms introduced in the previous section, the expected private gain from investment is $H(z F) B$. Suppose $k_{v}$ is distributed according to the probability distribution $R$, with corresponding density function $r, r\left(k_{v}\right)>0$ for $k_{v}>0$ and $r\left(k_{v}\right)=0$ otherwise. The potential victim invests whenever $k_{v}<\bar{k}_{v}=H(z F) B$, so the probability he invests is $R\left(\bar{k}_{v}\right)$. The expected net benefit from investment is

$$
R\left(\bar{k}_{v}\right) E\left(\bar{k}_{v}-k_{v} \mid k_{v}<\bar{k}_{v}\right)
$$

Differentiating the net benefit function with respect to $F$, we have

$$
R\left(\bar{k}_{v}\right) B z h(z F) .
$$

The investment benefit from increasing the fine is equal to the product of the marginal reduction in the probability of an offense, $z h(z F)$, and the expected gain among the pool of potential investors $R B$. Increasing the fine, through its deterrent effect, allows more of those who invest to realize their returns without having them destroyed by the offender. The expected net benefit 
from investment is maximized when the penalty is set at a level that eliminates the offender's gain, $F \geq M_{u} / z$, and minimized when the penalty is set at zero.

Of course, a social planner would not set out to maximize the expected net benefit from investment alone. The social objective is to maximize the net benefits from enforcement, which is equal to the sum of the net gain from investment and the net gain from offenses:

$$
\begin{aligned}
& N B=N B \text { (investment) }+N B(\text { offenses }) \\
& \quad=R\left(\bar{k}_{v}\right)\left(\bar{k}_{v}-E\left(k \mid k<\bar{k}_{v}\right)\right)+(1-H(z F))[E(M \mid M>z F)-(v+z c)]
\end{aligned}
$$

The solution is to internalize the direct losses of victims $(v)$, the marginal enforcement cost $(c)$, and the investment gain among the pool of potential victims that is forgone because of the fear of an offense $(R B)$. Formally, the optimal policy is as follows,

Proposition 3: Let $N B^{*}$ represent the value of the net benefit from enforcement under the optimal policy, and let $\overline{N B}$ represent the value of the net benefit from enforcement when offenses are completely deterred. Let $\bar{M}>v+z^{\prime} c+R\left(\bar{k}_{v}^{*}\right) B$ denote the value of $M_{u}$ such that $N B^{*}=\overline{N B}$. Then if $M_{u}>\bar{M}$, the optimal punishment policy is to set the penalty and probability of apprehension so that $F^{*}=\frac{v}{z^{\prime}}+c+\frac{R\left(\bar{k}_{v}^{*}\right) B}{z^{\prime}}$. If $M_{u} \leq \bar{M}$, then the optimal policy is to set the fine and the probability of apprehension so that $z F \geq M_{u}$.

In this case, the optimal penalty internalizes the investment return forgone as a result of the fear of offenses. In addition, the circumstances under which a complete deterrence policy is optimal are broader in this case. If the maximum gain to offenders $\left(M_{u}\right)$ is less than the marginal 
social cost of an offense, complete deterrence is optimal. However, even if the maximum gain exceeds the marginal social cost of an offense, complete deterrence may still be optimal, because the gain is still insufficient to compensate for the social cost of reduced investment.

This model applies obviously in the case where the offender burns down the crops and destroys the houses of farmers in his town. Fearing the loss of their crops, the farmers will be less willing to invest in planting seeds. Suppose, in view of the fear of crop damage, only half of the farmers are planting when the penalty is set at the optimal level; and that they expect to yield $\$ 5000$. The social gain from investment is $\$ 2500$. Let the direct harm from setting fire to the house be $\$ 10,000$, and the enforcement cost be $\$ 400$. If the minimum apprehension probability is 10 percent, the optimal penalty is $(\$ 10,000) /(.10)+(\$ 400)+(\$ 2500) /(.10)=\$ 125,400$.

In the antitrust law setting, this analysis applies to the cases in which firms allege that the exclusionary acts of a dominant firm have reduced the incentives to innovate. One frequently-expressed complaint during the Microsoft litigation was that the firm's aggressive tactics deterred innovation by smaller rivals in Silicon Valley. ${ }^{18}$ The optimal penalty derived in this section implies that antitrust enforcement should be more aggressive in the case where the defendant's conduct discourages innovation.

Although this policy recommendation is not easy to translate into legal standards, the general direction is clear. A rule-of-reason analysis should incorporate the investment effect as part of the evaluation of the anticompetitive harms of the dominant firm's conduct. ${ }^{19}$

\footnotetext{
18253 F.3d 34, 65 (D.C. Cir. 2001).

${ }^{19}$ It should be clear that the offender-investment and victim-investment models can be combined to yield an optimal penalty formula that balances opposing externalities. In the combined model, the penalty would be reduced relative the benchmark static penalty to the extent that punishment reduced the social gain from investment by the offender, and the penalty would be enhanced to the extent that punishment of the offender encouraged potential victims to invest. The net direction would be ambiguous a priori, but could easily be simulated in this model under various parameter assumptions. Segal and Whinston (2007) suggest that a policy that protects victims would be preferable
} 


\section{Headline Effects and Optimal Penalties}

In this part we consider the implications for optimal punishment when news headlines alter the investment decisions of offenders or victims. For example, a potential offender may read news headlines about punishments dealt to other offenders. The news headlines may lead the offender to believe that the likelihood of apprehension is greater than it is. Conversely, the offender may decide, because of the dearth of articles about offenders being punished, that the probability of apprehension is lower than it really is.

One simple way to model headline effects in the offender-investment case is to let the perceived probability of apprehension differ from the real probability of apprehension: $\tilde{z}=z(1+\mu)$. The optimal policy in this case is captured in the equation:

$$
F^{*}=\frac{1}{1+\mu}\left\{\frac{v}{z^{\prime}}+c-\frac{S}{z^{\prime}}\left(\frac{\psi\left(\bar{k}_{o}^{*}\right)\left(1-H\left(z^{\prime}(1+\mu) F^{*}\right)\right)}{\Psi\left(\bar{k}_{o}^{*}\right) h\left(z^{\prime}(1+\mu) F^{*}\right)+\psi\left(\bar{k}_{o}^{*}\right)\left(1-H\left(z^{\prime}(1+\mu) F^{*}\right)\right)^{2}}\right)\right\}
$$

Suppose offenders overestimate the likelihood of apprehension, so that $\mu>0$. The optimal fine can be examined as if it consists of two parts, one influencing incentives in the static setting (the first two terms) and the other part influencing the investment decision (the last two terms). In the absence of any investment with a social payoff, the optimal fine would be reduced

because it would frontload profits to new innovators (entrants). These considerations complicate the penalty analysis and raise questions about the ability of an enforcement authority to implement an optimal policy without committing errors. For example, a policy of protecting new innovators could be distorted in practice to protect unsuccessful innovators at the expense of successful innovators. 
to compensate for the offender's overestimate of the likelihood of apprehension. In addition, the reward for the residual surplus $W$ is reduced because the offender's overestimate reduces the size of the award necessary to induce him to invest. The total surplus component in (8) complicates matters, though. Because the portion of the penalty regulating the offender's incentives with respect to the total surplus is ambiguous, offender overestimation of the likelihood of apprehension could raise or lower that portion of the penalty. Moreover, it is plausible to think the investment effect would be amplified relative to the other terms, because the offender is likely to invest at an earlier time period in which he has the least information about the real probability of apprehension.

Now consider the investment decision of the victim. The victim invests while relying on news headlines to project the likelihood that he will reap the rewards of his investment. Suppose the break even cost level for the victim can be described as $\bar{k}_{v}=(1+\eta) H(z F) B$, where $\eta>0$ means that the victim underestimates the likelihood of an offense that destroys his investment. Now the optimal penalty satisfies

$$
F^{*}=\frac{v}{z}+c+\frac{R\left(\bar{k}_{v}^{*}\right) B-\eta(1+\eta) B^{2} r\left(\bar{k}_{v}^{*}\right) H(z F)}{z}
$$

which implies that the penalty assessed against the offender will be reduced when the victim underestimates the likelihood an offense. The penalty will be increased when the victim overestimates the likelihood of an offense. The reason for reducing the penalty when the victim underestimates is to align the private and social incentives to invest. If the victim thinks that 
there will not be an offense, he will invest too much in light of the objective return. The penalty is reduced in this case in order to indirectly diminish the investment incentives of the victim. ${ }^{20}$

The parameter $\eta$ can be considered an index of the alarm-to-danger ratio identified by Bentham (1789, at 153$)$. If $\eta$ is equal to zero, the danger and alarm caused by crime are the same. The impressions potential victims get from reading newspaper headlines are accurate indicators of the likelihood of an offense. If $\eta$ is positive, the alarm is less than the danger, and if $\eta$ is negative the alarm is greater than the danger. The optimal penalty in (9) implies that the penalty should increase as the alarm increases relative to the danger. The reason for this is that alarm has a discouraging effect on investment by potential victims. Given that, the penalty should be increased in order to internalize the negative investment effect.

\section{Discussion}

\section{A. Antitrust}

As we noted at the outset, the results of the optimal punishment literature do not translate easily into recommendations for the law. The models assume strict liability with casespecific optimal penalties. The law, in contrast, adopts cost-benefit tests and uses standardized penalties. Still, the results can be used to offer suggestions about the factors that should be considered in the legal standards.

The offender investment model, which incorporates innovation into monopoly regulation, suggests that the social innovation payoff from the effort to monopolize should be part of the rule of reason analysis conducted under Sherman Act Section 2. One could argue that

\footnotetext{
${ }^{20}$ A similar problem is encountered in the context of crime and victim precaution. The optimal fine varies in order to control the incentives of both the offender and the victim, see Hylton (1996).
} 
the law reflects this recommendation already - that is, that the optimal punishment model of this paper provides a justification for some basic features of existing Section 2 doctrine. Monopolization law does not hold monopolies per se liable under Section $2 .^{21}$ The law effectively immunizes firms from liability when they have merely acted as profit-maximizing monopolists. ${ }^{22}$ Liability is imposed under Section 2 for predatory conduct and efforts to exclude rivals. Exploitative conduct is distinguished from exclusionary conduct.

The law is underinclusive in its regulatory reach in comparison to the optimal penalty. An optimal "fine-tuned" approach to punishing monopolies would not provide a blanket exemption to firms that merely exploited their monopoly power. The optimal penalty would tax those firms by an amount equal to the consumer surplus transferred and destroyed and reward them for the consumer surplus created by their monopolization efforts, as in the case where the firm creates or expands a market through innovation and then monopolizes it. If the consumer surplus generated was small relative to the consumer surplus transferred and destroyed, the firm probably would pay a penalty even though all it did was exploit its monopoly power. If the penalty would reduce monopolization incentives more than investment incentives, the size (and likelihood) of a penalty would be greater. Antitrust law does not make such detailed distinctions. It formally exempts all firms that merely exploit their power.

An example should clarify this point. If a firm acquires its monopoly through exclusionary conduct (e.g., an exclusive dealing contract with a key resource supplier), it may be held liable under Section 2 of the Sherman Act. On the other hand, if a firm acquires its

\footnotetext{
${ }^{21}$ The legal standard is sometimes described as a balancing test that compares anticompetitive harms with procompetitive benefits, see U.S. v. Microsoft, 253 F.3d 34, 59 (D.C. Cir. 2001).

${ }_{22}$ In Alcoa, Judge Learned Hand distinguished monopolies that are passively acquired, and monopolies acquired through superior skill, foresight, and industry, from monopolies that are actively acquired. See Alcoa, 148 F.2d, at 429-431.
} 
monopoly because the firms supplying key resources to its rivals all go out of business, then the firm will not be found in violation of the Sherman Act. In both scenarios, the harm to consumers is the same. The law raises the threat of liability in the first scenario and exempts the firm in the second scenario. The optimal penalty model would impose the same penalties in both scenarios. If the firm made substantial market-creating investments in the first stage, the optimal penalty model explored here would punish the firm far more lightly than the static penalty examined in Landes (1983).

The exemption provided to firms that merely exploit their market power is not complete because of the risk of error. Any legal doctrine that distinguishes exploitation from exclusion will force courts to distinguish one from the other. Courts will make mistakes, which will force some firms that merely exploited their power to pay the same penalties as the firms that engaged in exclusion. Still, it is unlikely that these errors adjust antitrust law in its treatment of exploitation cases to the same point that is suggested by the punishment model of this paper. ${ }^{23}$

The exemption provided to firms that merely exploit their market power rather than engage in predation can be understood as a rough attempt in the law to take the welfare gains from innovation into account. One of the fundamental paradoxes of antitrust is that cartel pricing is treated as per se illegal, while monopoly pricing is per se lawful. ${ }^{24}$ That appears to be less of a paradox under this model. The general exemption for monopoly pricing can be understood as

\footnotetext{
${ }^{23}$ Baker (2005) argues that enforcement authorities are sensitive to innovation effects in their targeting decisions. If enforcement authorities could target only those cases in which the monopolization effect (i.e., elasticity with respect to the penalty) was substantially greater than the investment effect, then Baker's argument suggests that antitrust enforcement, in the presence of some enforcement error, may be approximately optimal. But if the two elasticities are equal or close (even though the monopolization effect exceeds the investment effect), enforcement would reduce society's wealth.

${ }^{24}$ This point served as a key justification for Judge Learned Hand's reform of monopolization law in his Alcoa opinion. Hand argued that monopolies (monopoly pricing) should be viewed in the same way as cartels (cartel pricing). Alcoa, 148 F.2d., at 427-29. For an informal discussion of innovation and its implications for Hand's argument, see Evans and Hylton (2008).
} 
the law's attempt to avoid punishment that discourages innovation. Firms are not allowed to gain a direct subsidy for innovation through the law, but they are also not punished for exploiting the monopoly power that results from innovation.

For firms that engage in conduct that is deemed exclusionary the law is overinclusive, in the sense that it does not formally aim to reduce penalties for the firms that have created or expanded their markets through innovation. One exception to this is United States v. Jerrold Electronics Corp. ${ }^{25}$ The court held that rule of reason analysis rather than per se liability, applied to Jerrold's tying policies that were instituted at a time when the market for antennae systems was in its infancy. Jerrold had played a big role in the creation of the market. The court's decision exempted Jerrold from antitrust liability for the infancy period of its business, which can be viewed as a penalty reduction based on innovation.

The optimal penalty model implies that the doctrine of Jerrold Electronics should operate generally in cases involving abuse of monopoly power, whether it is tying or exclusive dealing, as long as the firm's exclusionary acts were necessary in securing a break-even return for its market-expanding investment.

A symmetrical and opposing conclusion can be reached where the dominant firm's conduct discourages the innovation of rivals. The victim investment model suggests that the rule of reason balancing under Section 2 should take into account credible evidence that the dominant firm's conduct reduced innovation by potential competitors. Of course, counterfactual arguments about innovation that would have occurred are difficult to assess with confidence. If courts were to take negative innovation effects into account under the monopolization law, some effort would have to be made to weed out spurious claims.

${ }^{25} 187$ F. Supp. 545 (E.D. Pa. 1960), aff’d per curiam, 365 U.S. 567 (1961). 
When internalization is the optimal punishment approach, a rule of reason analysis would appear to be the proper framework in the law. In the rule of reason analysis, some attempt would be made to compare the social benefits from the dominant firm's innovation with the social costs of its discouragement of innovation by rivals. Both are important externalities that could tilt the court's analysis either away or toward a finding of liability (Segal and Whinston, 2007).

To be more concrete, the rule-of-reason test for monopolization has been described as a balancing test which compares the anticompetitive harms with the procompetitive benefits of the firm's conduct. The anticompetitive harms portion of the test is primarily concerned with the static harm to consumer welfare. At this stage of the analysis, the court is concerned with the monopoly surcharge and the deadweight loss imposed on society. According to U.S. v. Microsoft, the plaintiff bears the burden of proving a substantial harm to consumer welfare. ${ }^{26}$ Under Microsoft, the burden then shifts to the defendant to either prove that there was no substantial consumer harm or to proffer a procompetitive benefit. In a case in which consumer harm cannot be disproved, the obvious implication is that the defendant would point to efficiency gains that were passed on to consumers or to society offsetting the consumer harm from monopolistic pricing. For example, in the case of an exclusive-dealing contract that reduces supply costs, the defendant would point to the efficiency gains to society, and especially those to consumers as a counterweight to the plaintiff's proof of harm to consumer welfare. This paper points to a special category of procompetitive benefit, the residual consumer surplus from innovation, that should also serve as a counterweight in the balancing test. Even in the case in which the defendant could point to no efficiency gains from its exclusionary conduct (such as an

${ }^{26} 253$ F.3d 34, 59 (D.C. Cir. 2001). 
exclusive dealing contract), the court should take into account the residual gains to consumers ( $W$ in Figure 1) from the defendant's first-stage innovation.

Our division of the optimal punishment models into "static" and "dynamic" categories is to some degree inappropriate. The key factor distinguishing the "static" model from the "dynamic" offender investment model is the existence of a positive externality in the latter model. It happens that the positive externality is connected to innovation, which is typically associated with dynamic models. However, any positive externality connected to the firm's monopolization, whether from investment in innovation or some other source, would require the inclusion of a subsidy component in the optimal penalty. ${ }^{27}$

\section{B. Penalties and Torts Generally}

The model developed here has implications for the literature on optimal damages. Polinsky and Shavell (1992), building on Becker (1968), concluded that the "optimal fine equals the harm, properly inflated for the chance of not being detected, plus the variable enforcement cost of imposing the fine." Polinsky and Shavell (1998) applied this theory to punitive damages in torts.

The existing literature on penalties does not incorporate, as this paper does, the investment effects of offensive conduct or of punishment. When either offensive conduct or its punishment effect socially productive investment, the optimal penalty formula differs from the standard recommendation reflected in Polinsky and Shavell (1992).

\footnotetext{
${ }^{27}$ In the same vein, the description of the static model penalty here as the Becker-Landes penalty is contestable. Becker did examine innovation as a special case of his model, and noted that a subsidy or prize would be optimal (Becker, at 202-204). However, Becker did not extend his model to the case in which the offender both inflicts injuries and benefits society through innovation. Landes's application of the Becker model is restricted to the static case in which the monopoly does not invest in innovation.
} 
Consider the case in which offensive conduct discourages investment decisions of potential victims. This case was first considered by Bentham, who referred to the "secondary effects" of criminal behavior (Bentham 1789, at 153). According to Bentham, offensive conduct leads to primary and secondary harms to society. The primary harms are the direct and derivative losses, as well as the enforcement costs. The secondary harms are the costs that result from the discouraged investment and extend "either over the whole community, or over some multitude of unassignable individuals" (Bentham, at 153). Secondary effects could include a wide range of costs generated by changes in behavior in response to the fear of crime. Bentham argued that punishment should be enhanced to reflect the secondary costs of crime. This paper models a specific type of secondary cost - the investment decision - and shows the precise formula for optimal punishment. The formula implies, in agreement with Bentham, that the optimal penalty should be enhanced to internalize the secondary costs of offensive conduct to the offenders.

Another type of secondary effect unexamined in the previous literature is the case in which punishment for an offense itself affects productive investment decisions by the offender. This is the case examined in the offender investment model.

The investment models have implications for the theory of tort remedies. The damage multiplier approach of Polinsky and Shavell (1998) suggests that the optimal tort damage award will divide the harm by the probability of liability. However, this is inadequate as a method of internalizing social costs when there are substantial negative investment effects from offenses.

Conversely, the damage multiplier approach overdeters when the offender's investment in some activity yields a positive externality (e.g., product innovation) and is dependent on profits from a later action that causes harm, as in the innovation-monopolization model examined 
above. This implies that strict liability, coupled with a damage multiplier, is inappropriate in settings in which the offender is responsible for a significant positive externality.

For example, suppose the firm invests in a new vaccine in the first period. In the second period, when the product is on the market, it can take precaution to reduce the likelihood of harm to consumers. The precaution could take many different forms: enhancing the warning label, or better monitoring of the production process. The firm decides in the second period whether to take the precaution by comparing the cost of precaution to the expected fine. This description of the vaccine marketing is analogous to the investment-monopolization model examined earlier. It follows that the optimal penalty will depend on several factors: the harm to the consumer, the positive externality to society (consumer surplus from innovation and other beneficial externalities from vaccination), the degree to which an increase in the penalty affects the investment incentive versus the precaution incentive. As in the monopolization problem examined earlier, the optimal punishment may be no punishment at all - or even a subsidy.

Obviously, this has implications for strict products liability. In particular, strict products liability may not be optimal in the innovation setting, in which the firm's investment has generated a substantial positive externality such as the creation of a market, or in a setting in which the firm's product marketing yields beneficial spillovers (e.g., vaccines). ${ }^{28}$ As long as the injuries caused by the product are not too large in relation to the surplus created, the negligence standard would be preferable.

\footnotetext{
${ }^{28}$ In the case of drugs, the law has shown some signs of incorporating this implication, though the record is mixed. Comment k of Restatement (Second) of Torts, Section 402A, suggests that courts should exempt drug makers from strict liability for product defects and defective designs. In Brown v. Superior Court, 44 Cal. 3d 1049 (1988), the California Supreme Court held that comment k insulated all Food and Drug Administration-approved prescription drugs from strict liability for design defect. The Court reasoned that strict liability would deter innovation of new drugs. The California courts later applied the same reasoning to implanted prescription medical devices; see Artiglio v. Superior Court, 22 Cal. App. 4th 1388 (1994); Plenger v. Alza Corp., 11 Cal. App. 4th 349 (1992). However, Brown appears to have been adopted in only a minority of U.S. states.
} 


\section{Conclusion}

Using a simple model of punishment based on strict liability with monetary penalties, we have examined the design of optimal penalties when actors make investment decisions that are affected by the penalty. One important scenario examined is that in which the offender invests in some activity that benefits society, and the private return to that activity is a function of the offense he later commits as well as the penalty for that offense. In this scenario, the optimal penalty will attempt to internalize the social costs of the offender's conduct and also encourage investment. In the monopolization setting, this implies that the optimal monetary penalty will not necessarily internalize the consumer harm caused by the monopolist's exclusionary conduct. The optimal penalty will include a subsidy for innovation, and may be on net a reward.

The same result applies to the product safety scenario. If the firm invests in a product that creates a new market, the optimal penalty will not necessarily internalize the harm to victims caused by product defects. Since the optimal penalty will include a reward for innovation, it may be zero, or negative (i.e., a reward). 
Appendix

Proof of Proposition 1: The social planner's problem is to choose $z$ and $F$ to minimize

$$
\begin{aligned}
C & =H(z F)(E(M \mid M \leq z F))+(1-H(z F))(v+z c) \\
& =\int_{0}^{z F} M h(M) d M+(1-H(z F))(v+z c)
\end{aligned}
$$

The first-order conditions are:

$$
\begin{aligned}
& \frac{\partial C}{\partial F}=-z h(z F)(v+z c-z F) \\
& \frac{\partial C}{\partial z}=-F h(z F)(v+z c-z F)+(1-H(z F)) c
\end{aligned}
$$

Note that when $z^{*}$ and $F^{*}$ are chosen so that $z^{*} F^{*}$ is greater than $M_{u}$, then the offender is completely deterred and the above equation equals to $E(M)$. We discuss the optimal choice of enforcement rate and penalty below.

(1) $v+z^{\prime} c \geq M_{u}$

This is the case where the minimum cost from an offense is higher than the maximum benefit to the offender. In this case it is optimal to eliminate offenses by setting $z^{*} F^{*}$ is greater than $M_{u}$. Here is the proof.

$$
\begin{aligned}
C & =H(z F)(E(M \mid M \leq z F))+(1-H(z F))(v+z c) \geq H(z F)(E(M \mid M \leq z F))+(1-H(z F)) M_{u} \\
& >H(z F)(E(M \mid M \leq z F))+(1-H(z F))(E(M \mid M \geq z F))=E(M)
\end{aligned}
$$

In this scenario, $E(M)$ is the lower bound for social cost, as in Figure A1. Given a specific enforcement rate $\mathrm{z}, F^{*} \in\left\{F: F \geq M_{u} / \mathrm{z}\right\}$.

(2) $v+c<M_{u}$

Given a specific value of $\mathrm{z}$, let $F^{*}=\frac{v}{z}+c$ and $F^{L}=\frac{M_{u}}{z}$. Note here that $F^{*}<F^{L}$. When $F<F^{*}, C$ is decreasing and when $F>F^{*}, C$ is increasing until it reaches $E(M)$ for $\forall F \geq F^{L}$. Figure A2 shows the relationship. Thus for a given $z$, the optimal choice of $F$ is $F^{*}$. 
Moreover, given $F^{*}, C$ is increasing in $z$ so that it is optimal to set $z^{*}=z^{\prime}$. Consequently, the optimal policy is $\left\{z^{*}=z^{\prime}, F^{*}=\frac{v}{z^{\prime}}+c\right\}$ and the corresponding social cost is $C^{*}=H\left(v+z^{\prime} c\right)\left(E\left(M \mid M \leq v+z^{\prime} c\right)\right)+\left(1-H\left(v+z^{\prime} c\right)\right)\left(v+z^{\prime} c\right)$. Note that $C^{*}$ is smaller than $E(M)$.

(3) $v+z^{\prime} c<M_{u} \leq v+c$

Using the same logic, we know that given a specific value of $z$, the optimal $F$ is $F^{*}=\frac{v}{z}+c$. Depending on the value of $\mathrm{z}$, now $F^{*}$ may be smaller or bigger than $F^{L}$. As for $\forall F \geq F^{L}, C$ remains at the level $E(M)$ so it would be better to have $F^{*}<F^{L}$ so that we could reach the cost level less than $E(M)$. Thus in this scenario, the optimal policy is again reached when $z$ is set at its minimal level and $F$ equals to $F^{*}$, namely, $\left\{z^{*}=z^{\prime}\right.$, $\left.F^{*}=\frac{v}{z^{\prime}}+c\right\}$

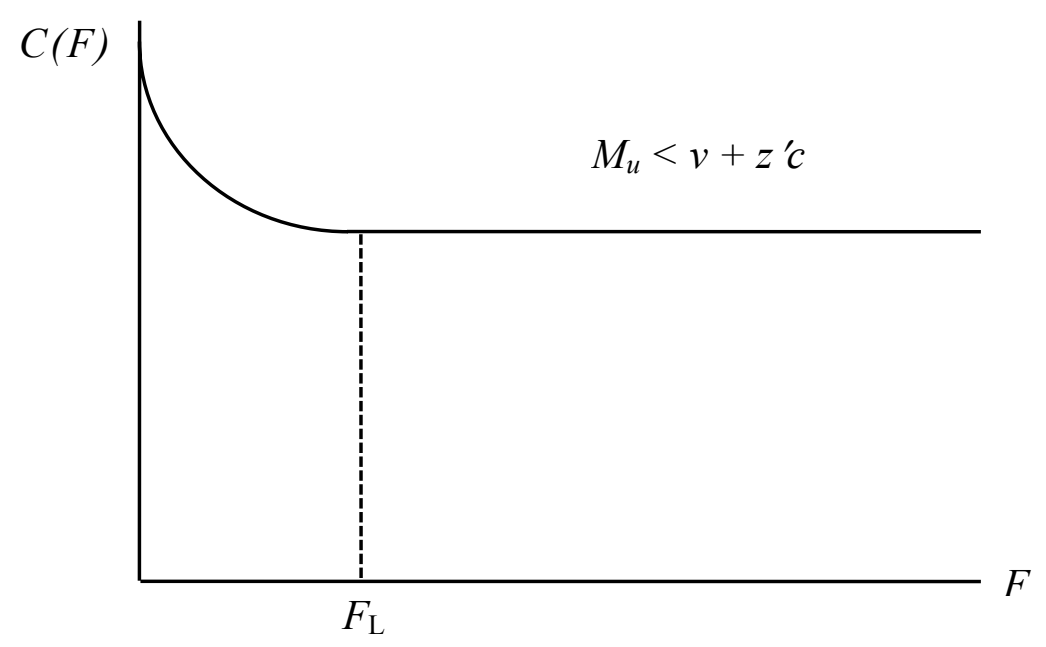

Figure A1 


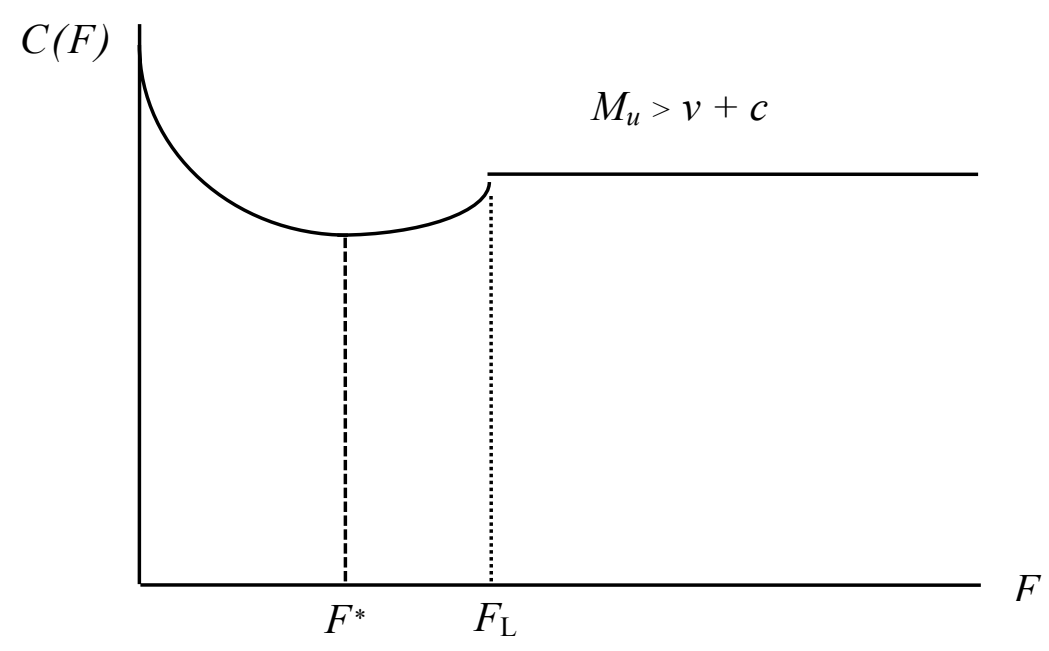

Figure A2

Proof of Proposition 2: The proof follows in three steps.

First, we show that it is never optimal to set $z^{*} F^{*}$ greater than $M_{u}$. If $z^{*} F^{*} \geq M_{u}$, the offender will not make any investment and there will be no social gain. Instead, for any $z^{*} F^{*}<M_{u}$, we observe a positive social benefit as

$$
\begin{aligned}
& N B>\Psi\left(\overline { k } _ { o } ^ { * } ( 1 - H ( z F ^ { * } ) ) \left\{\left(1-H\left(z F^{*}\right) E\left(M \mid M>z F^{*}\right)-\bar{k}_{o}^{*}+\left(1-H\left(z F^{*}\right)(S-v-z c)+H\left(z F^{*}\right) S\right\}\right.\right.\right. \\
& =\Psi\left(\bar{k}_{o}^{*}\right)\left\{\left(1-H\left(z F^{*}\right)\left(z F^{*}+S-v-z c\right)+H\left(z F^{*}\right) S\right\}\right. \\
& =\Psi\left(\bar{k}_{o}^{*}\right) \frac{\Psi\left(\bar{k}_{o}^{*}\right) h\left(z F^{*}\right)}{\Psi\left(\bar{k}_{o}^{*}\right) h\left(z F^{*}\right)+\psi\left(k^{*}\right)\left(1-H\left(z F^{*}\right)\right)^{2}} S>0
\end{aligned}
$$

Second, we need to prove that the optimal penalty $F^{*}$ is the unique solution to the global maximum. The first order condition (equation 3 in the paper) can be simplified as follows: 


$$
\begin{aligned}
& \frac{\partial N B}{\partial F}=(v+z c-z F)\left\{\Psi\left(\bar{k}_{o}\right) h(z F)+\psi\left(\bar{k}_{o}\right)(1-H(z F))^{2}\right\}-S\left\{\psi\left(\bar{k}_{o}\right)(1-H(z F))\right\} \\
& =\frac{P}{z}\left\{\frac{v}{z}+c-F-\frac{S}{z} \theta\right\}
\end{aligned}
$$

where $P=\Psi\left(\bar{k}_{o}\right) h(z F)+\psi\left(\bar{k}_{o}\right)(1-H(z F))^{2}$ and $\quad \theta=\frac{\psi\left(\bar{k}_{o}\right)(1-H(z F))}{P}$. Since $P>0, \quad$ if there exists $F^{*}$ such that

$$
F=\frac{v}{z}+c-\frac{S}{z} \theta(F)
$$

then we will have $\left.\frac{\partial N B}{\partial F}\right|_{F=F^{*}}=0$.

To proceed, let's first take a look at $\theta$, which is a function of $F$. When $F \leq 0, \theta=1$; when $F>0, \theta$ is strictly increasing in $F$ because (1) $\frac{\Psi\left(\bar{k}_{o}\right)}{\psi\left(\bar{k}_{o}\right)}$ is increasing in $\bar{k}_{o}$ and $\bar{k}_{o}$ is decreasing in $F ;(2) \frac{h(z F)}{(1-H(z F))}$ is decreasing in $F ;(3)(1-H(z F))$ is decreasing in $F$; (4) both $\frac{\Psi\left(\bar{k}_{o}\right)}{\psi\left(\bar{k}_{o}\right)}$ and $\frac{h(z F)}{(1-H(z F))}$ are positive.

Let $\theta_{\min }$ be the value of $\theta$ when $F$ is approaching zero. It is straightforward that $\theta_{\min }=\lim _{F \rightarrow 0} \theta=\frac{\psi\left(\bar{k}_{o}\right)}{\Psi\left(\bar{k}_{o}\right) h(z F)+\psi\left(\bar{k}_{o}\right)}<1$. [The value of $\theta_{\min }$ will depend on the shape of the distributional forms of $\psi(\cdot)$ and $H(\cdot)$. For example if we assume that both of them 
take an exponential form with mean of $1 / \lambda^{\psi}$ and $1 / \lambda^{H}$, then $\left.\theta_{\min }=\frac{1}{\left(\lambda^{H} / \lambda^{\psi}\right)\left(e^{\lambda^{\psi} / \lambda^{H}}-1\right)+1}<\frac{1}{2} \cdot\right]$

Let's then consider equation (2B). The left-hand side (LHS) of equation (2B) is $F$ itself, which could be treated as strictly increasing function of $F$. The right-hand side (RHS) then is a nonincreasing function where

$$
R H S=\left\{\begin{array}{l}
\frac{v}{z}+c-\frac{S}{z} \text { if } F \leq 0 \\
\frac{v}{z}+c-\frac{S}{z} \theta \text { if } F>0
\end{array}\right.
$$

and the RHS reaches its maximum at $\frac{v}{z}+c-\frac{S}{z} \theta_{\min }$ when $F \rightarrow 0$. The following three cases are explained for the equality of the $L H S$ and $R H S$.

Case 1: $\frac{v}{z}+c-\frac{S}{z} \geq 0$

It is obvious that in this case, $\frac{v}{z}+c-\frac{S}{z} \theta_{\min }>0$. There exists a unique solution such that $L H S=R H S$ and the unique equilibrium is $F^{*}=\frac{v}{z}+c-\frac{S}{z} \theta^{*}>0$. The proof of the global maximum is quite straightforward: when $F<F^{*},\left.\frac{\partial N B}{\partial F}\right|_{F<F^{*}}>0$; and when $F>F^{*}$, $\left.\frac{\partial N B}{\partial F}\right|_{F>F^{*}}<0$. This case corresponds to the graph in Figure A3 below. 


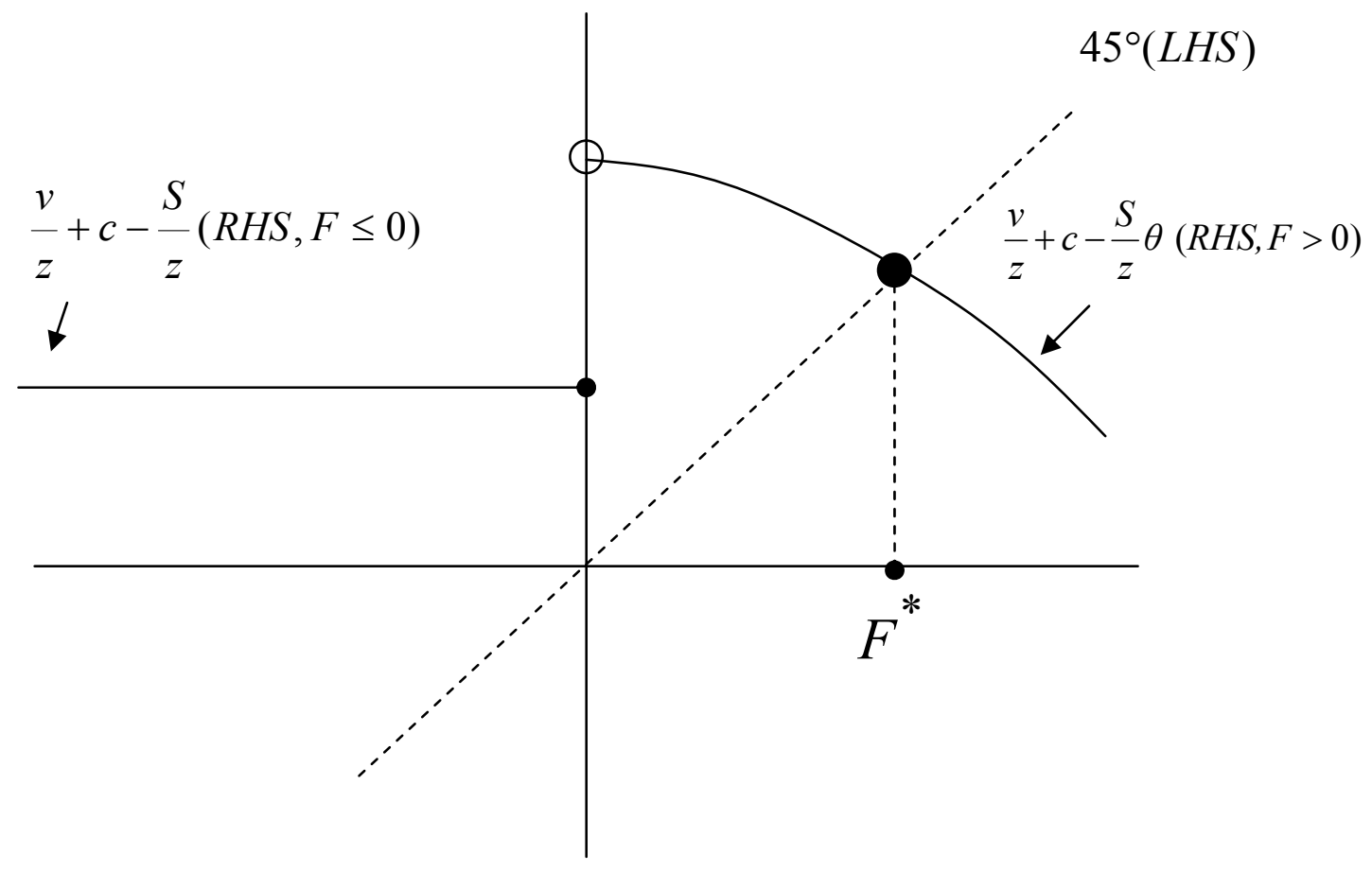

Figure A3: Case 1

Case 2: $\frac{v}{z}+c-\frac{S}{z}<0$ and $\frac{v}{z}+c-\frac{S}{z} \theta_{\min }<0$

Again we obtain a unique optimum $F^{*}=\frac{v}{z}+c-\frac{S}{z}<0$ for $L H S=R H S . F^{*}$ is the global maximum as when $F<F^{*},\left.\frac{\partial N B}{\partial F}\right|_{F<F^{*}}>0$; and when $F>F^{*},\left.\frac{\partial N B}{\partial F}\right|_{F>F^{*}}<0$. This case corresponds to the graph in Figure A2. 


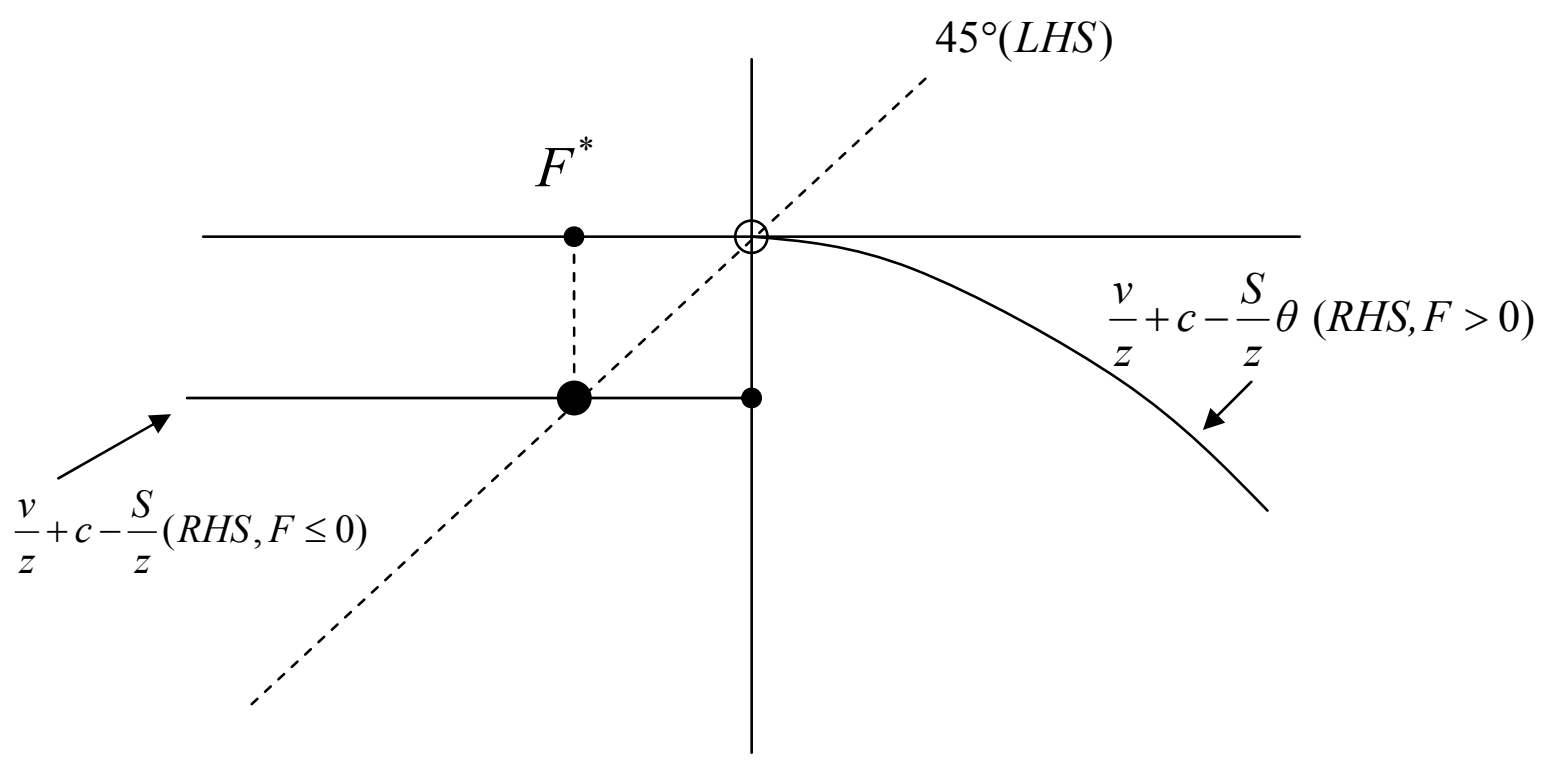

Figure A4: Case 2

Case 3: $\frac{v}{z}+c-\frac{S}{z}<0$ and $\frac{v}{z}+c-\frac{S}{z} \theta_{\min } \geq 0$

There exist two $F^{*}$ (one for $F^{*}<0$ and the other for $F^{*} \geq 0$ ) such that $L H S=R H S$ : $F_{1}^{*}=\frac{v}{z}+c-\frac{S}{z}<0$ and $F_{2}^{*}=\frac{v}{z}+c-\frac{S}{z} \theta^{*}>0$. It can be verified that both are local maximums since $\left.\quad \frac{\partial N B}{\partial F}\right|_{F<F_{1}^{*}}>0$ and $\left.\quad \frac{\partial N B}{\partial F}\right|_{0 \geq F>F_{1}^{*}}<0 ; \quad$ and $\left.\quad \frac{\partial N B}{\partial F}\right|_{0<F<F_{2}^{*}}>0$ and $\left.\frac{\partial N B}{\partial F}\right|_{F>F_{2}^{*}}<0$. The solutions are illustrated in Figure A5. The global maximum is the $F^{*}$ that provides the higher social benefit. 


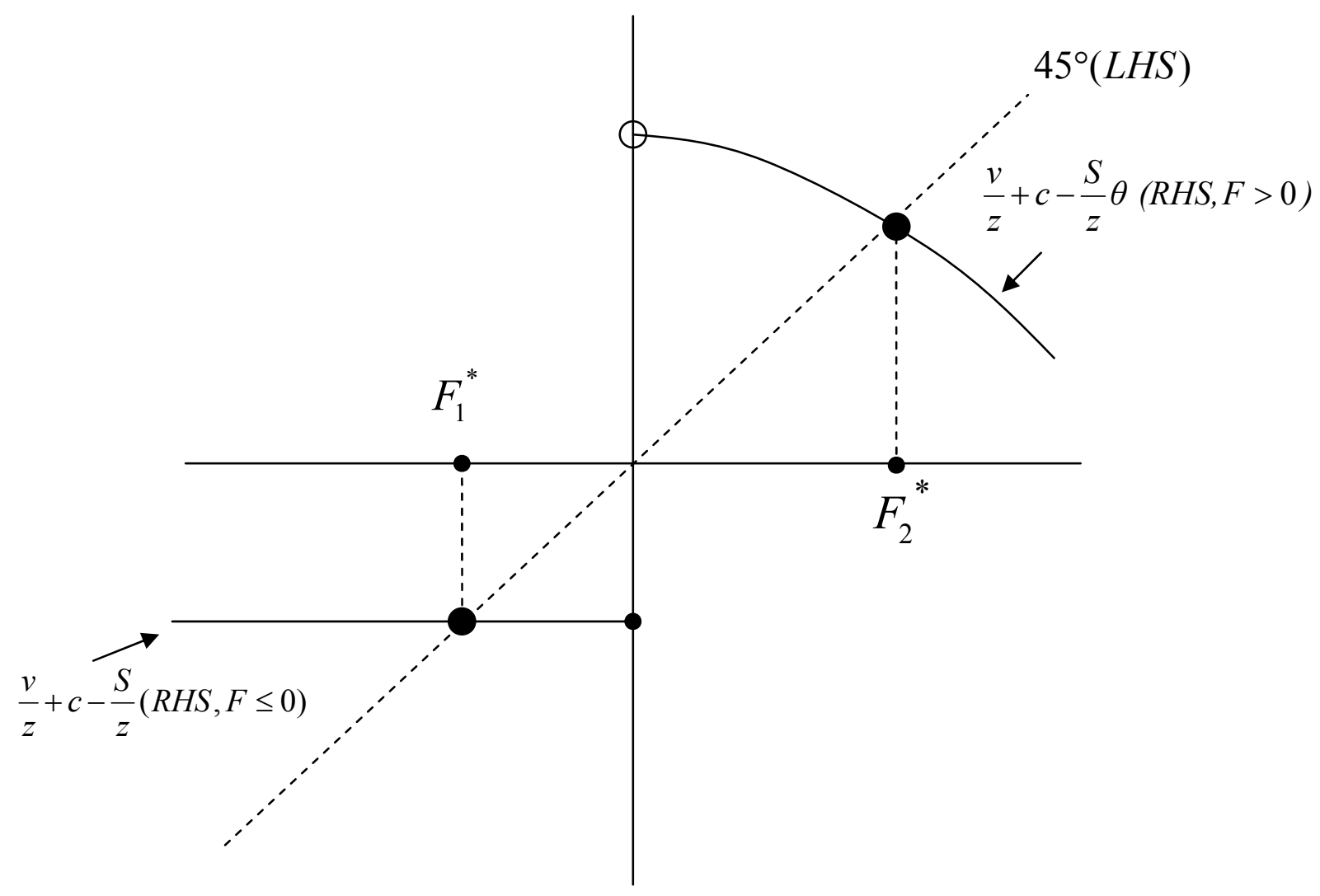

Figure A5: Case 3

Consider the following comparison of the two $F^{*}$ solutions:

$F_{1}^{*}=\frac{v}{z}+c-\frac{S}{z}<0$ so that $\bar{k}_{o}^{1}=\bar{M}-z F_{1}^{*}=\bar{M}+S-v-z c$

$N B_{1}=\Psi\left(\bar{k}_{o}^{1}\right)\left\{\bar{M}-E\left(k \mid k<\bar{k}_{o}^{1}\right)+(S-v-z c)\right\}$

$=\Psi\left(\bar{k}_{o}^{1}\right) \bar{k}_{o}^{1}-\int_{0}^{\bar{k}_{o}^{1}} k \psi(k) d k$

$F_{2}^{*}=\frac{v}{z}+c-\frac{S}{z} \theta^{*}>0$ so that $\bar{k}_{o}^{2}=\int_{z F_{2}} M h(M) d M-\left(1-H\left(z F_{2}^{*}\right)\right) z F_{2}^{*}<\bar{k}_{o}^{1}$ 


$$
\begin{aligned}
& N B_{2}=\Psi\left(\bar{k}_{o}^{2}\right)\left\{\left(1-H\left(z F_{2}^{*}\right)\right) E\left(M \mid M>z F_{2}^{*}\right) \bar{M}-E\left(k \mid k<\bar{k}_{o}^{2}\right)+\left(1-H\left(z F_{2}^{*}\right)\right)(S-v-z c)+H\left(z F_{2}^{*}\right) S\right. \\
& =\Psi\left(\bar{k}_{o}^{2}\right)\left\{\bar{k}_{o}^{2}+\left(1-H\left(z F_{2}^{*}\right)\right) z F_{2}^{*}-E\left(k \mid k<\bar{k}_{o}^{2}\right)+\left(1-H\left(z F_{2}^{*}\right)\right)(S-v-z c)+H\left(z F_{2}^{*}\right) S\right. \\
& =\Psi\left(\bar{k}_{o}^{2}\right) \bar{k}_{o}^{2}-\int_{0}^{\bar{k}_{o}^{2}} k \psi(k) d k+S-S\left(1-H\left(z F_{2}^{*}\right)\right) \theta^{*}
\end{aligned}
$$

Note that $\theta^{*}$ must be smaller than one since $F_{1}^{*}=\frac{v}{z}+c-\frac{S}{z}<0 \quad$ and $F_{2}^{*}=\frac{v}{z}+c-\frac{S}{z} \theta^{*}>0$. Also note that $\Psi\left(\bar{k}_{o}\right) \bar{k}_{o}-\int_{0}^{\bar{k}_{o}} k \psi(k) d k$ is strictly increasing in $\bar{k}_{o}$ and $\quad \bar{k}_{o}^{2}<\bar{k}_{o}^{1}$, we have $\Psi\left(\bar{k}_{o}^{1}\right) \bar{k}_{o}^{1}-\int_{0}^{\bar{k}_{o}^{1}} k \psi(k) d k>\Psi\left(\bar{k}_{o}^{2}\right) \bar{k}_{o}^{2}-\int_{0}^{\bar{k}_{o}^{2}} k \psi(k) d k$. Still, $N B_{2}$ could be greater than $N B_{1}$ given a large enough $S$. The net subsidy solution $F_{1}^{*}$ is preferable to the penalty $F_{2}{ }^{*}$ if the enhanced wealth from additional investment is greater than the wealth gained from deterring monopolization with the penalty.

Lastly, we show that it is optimal to set $z=z^{\prime}$. The first-order condition with respect to $\mathrm{z}$ is as follows,

$$
\begin{gathered}
\frac{\partial N B}{\partial z}=F(v+z c-S-z F)\left\{\Psi\left(\bar{k}_{o}\right) h(z F)+\psi\left(\bar{k}_{o}\right)(1-H(z F))^{2}\right\}-\psi\left(\bar{k}_{o}\right)(1-H(z F)) c \mathbb{F} \\
-F S\left\{\psi\left(\bar{k}_{o}\right) H(z F)(1-H(z F))-\Psi\left(\bar{k}_{o}\right) h(z F)\right\}
\end{gathered}
$$

Given that $F=F^{*},\left.\frac{\partial N B}{\partial z}\right|_{F=F^{*}}=-\psi\left(\bar{k}_{o}\right)\left(1-H\left(z F^{*}\right)\right) c<0$ so that it is optimal to choose the minimum enforcement rate.

Proof of Proposition 3: The social welfare function can be expressed as

$$
N B=R\left(\bar{k}_{v}\right)\left(\bar{k}_{v}-E\left(k \mid k<\bar{k}_{v}\right)\right)+(1-H(z F))\{E(M \mid M>z F)-(v+z c)\}
$$


where $\bar{k}_{v}=H(z F) B$.

Assume that $z F<M_{u}$. The two first-order conditions for the welfare maximization problem are:

$\frac{\partial N B}{\partial F}=R\left(\bar{k}_{v}\right) B z h(z F)+z h(z F)(z c+v-z F)$

where the first term denotes marginal gain from investment; and $\frac{\partial N B}{\partial z}=F h(z F)\left(z c+v-z F+R\left(\bar{k}_{v}\right) B\right)-(1-H(z F)) c$

Using the same logic of the basic model (see Proposition 1), it is easy to show that for a given value of $\mathrm{z}, F$ is optimally set so that $F^{*}=\frac{v}{z}+c+\frac{R\left(\bar{k}_{v}^{*}\right) B}{z}$. And since $N B$ is decreasing in $\mathrm{z}$ when $F^{*}=\frac{v}{z}+c+\frac{R\left(\bar{k}_{v}^{*}\right) B}{z}$, it is optimal to choose enforcement rate at its minimal level, namely $z^{*}=z^{\prime}$.

Now let $N B^{*}$ denote the social welfare evaluated at $\left(z^{\prime}, F^{*}\right)$, namely,

$$
N B^{*}=R\left(\bar{k}_{v}^{*}\right)\left(\bar{k}_{v}^{*}-E\left(k \mid k<\bar{k}_{v}^{*}\right)\right)+\left(1-H\left(z^{\prime} F^{*}\right)\right)\left\{E\left(M \mid M>z^{\prime} F^{*}\right)-\left(v+z^{\prime} c\right)\right\}
$$

And let $\overline{N B}$ be the social welfare evaluated when $F^{*} \in\left\{F: F \geq M_{u} / z\right\}$. In this latter scenario, the offense is completely deterred and social welfare depends solely on the victim's net gain from investment, where $\overline{N B}=R(B)\left[B-E\left(k_{v} \mid k_{v}<B\right)\right]$.

(1) $M_{u} \leq v+z^{\prime} c+R\left(\bar{k}_{v}^{*}\right) B$

In this case, it is optimal to set $z^{*} F^{*}$ greater than $M_{u}$ as $N B^{*}$ is smaller than $\overline{N B}$. 


$$
\begin{aligned}
& N B^{*}-\overline{N B}<R\left(\bar{k}_{v}^{*}\right)\left(\bar{k}_{v}^{*}-E\left(k \mid k<\bar{k}_{v}^{*}\right)\right)+\left(1-H\left(z^{\prime} F^{*}\right)\right)\left(M_{u}-\left(v+z^{\prime} c\right)\right)-R(B)\left[B-E\left(k_{v} \mid k_{v}<B\right)\right] \\
& \leq R\left(\bar{k}_{v}^{*}\right)\left(\bar{k}_{v}^{*}-E\left(k \mid k<\bar{k}_{v}^{*}\right)\right)+\left(1-H\left(z^{\prime} F^{*}\right)\right) R\left(\bar{k}_{v}^{*}\right) B-R(B)\left[B-E\left(k_{v} \mid k_{v}<B\right)\right] \\
& =\int_{\vec{k}_{v}}^{B} k r(k) d k-B \int_{\bar{k}_{v}^{*}}^{B} r(k) d k \\
& <B \int_{\vec{k}_{v}^{*}}^{B} r(k) d k-B \int_{\vec{k}_{v}^{*}}^{B} r(k) d k=0
\end{aligned}
$$

(2) $M_{u}>v+z^{\prime} c+R\left(\bar{k}_{v}^{*}\right) B$

First, let $\Delta=N B^{*}-\overline{N B}$ and it is easy to show that $\Delta$ is increasing in $M_{u}$ as

$$
\frac{\partial \Delta}{\partial M_{u}}=M_{u} h\left(M_{u}\right) \text {. }
$$

Let $\bar{M}$ denote the value of $M_{u}$ such that $N B^{*}-\overline{N B}=0$. Based on case (1), it is obvious that $\bar{M}$ is bigger than $v+z^{\prime} c+R\left(\bar{k}_{v}^{*}\right) B$. For $M_{u} \in\left\{M_{u}: M_{u}>\bar{M}\right\}, N B^{*}>\overline{N B}$ so that $\left\{z^{\prime}, F^{*}\right\}$ is the optimal policy; for $M_{u} \in\left\{M_{u}: v+z^{\prime} c+R\left(\bar{k}_{v}^{*}\right) B<M_{u} \leq \bar{M}\right\}, N B^{*} \leq \overline{N B}$ so that $z^{*} F^{*}>M_{u}$ is the optimal policy. 


\section{References}

Philippe Aghion, Nicholas Bloom, Richard Blundell, Rachel Griffith, and Peter Howitt, Competition and Innovation: An Inverted-U Relationship, 120 Quarterly Journal of Economics, $701-728$ (2005).

Jonathan Baker, Private Enforcement and the Deterrent Effect of Antitrust Damage Remedies, 4 J. Law, Econ. \& Organization 385 (1988).

Jonathan Baker, Beyond Schumpeter vs. Arrow: How Antitrust Fosters Innovation, 74 Antitrust Law Journal, 575-602 (2007).

Gary S. Becker, Crime and Punishment: An Economic Approach, 76 J. Pol. Econ. 169 (1968).

Jeremy Bentham, The Principles of Morals and Legislation (1789).

David S. Evans and Keith N. Hylton, The Lawful Acquisition and Exercise of Monopoly Power and Its Implications for the Objectives of Antitrust, 4 Competition Policy International, 203-241, 2008.

David S. Evans and Richard Schmalensee, Some Economic Aspects of Antitrust Analysis in Dynamically Competitive Industries, in INNOVATION POLICY AND THE ECONOMY, 1-49, Volume 2, Adam B. Jaffe, Josh Lerner, and Scott Stern eds., (Cambridge, MA, and London: MIT Press, 2002).

Louis Kaplow, The Patent-Antitrust Intersection: A Reappraisal, 97 Harvard Law Review 1813 (1984).

Keith N. Hylton, Optimal Law Enforcement and Victim Precaution, 27 RAND J. Econ. 197 (1996).

Glenn C. Loury Market Structure and Innovation, 93 Quarterly Journal of Economics, 395-410 (1979)

William M. Landes, Optimal Sanctions for Antitrust Violations, 50 U. Chicago L. Rev. 652 (1983).

Tom Lee and Louis L. Wilde, Market Structure and Innovation: A Reformulation, 94 Quarterly Journal of Economics, 429-436 (1980).

Edward Mason, Schumpeter on Monopoly and the Large Firm, 33 Rev. Econ. \& Statistics, 139-144 (1951).

John Peterman, The International Salt Case, 22 J. Law \& Econ. 351 (1979). 
A. Mitchell Polinsky and Steven Shavell, Enforcement Costs and the Optimal Magnitude and Probability of Fines, 35 J. Law \& Econ. 133 (1992)

A. Mitchell Polinsky and Steven Shavell, Punitive Damages: An Economic Analysis, 111 Harvard Law Review 869 (1998).

Joseph Schumpeter, Capitalism, Socialism, and Democracy (1943).

Ilya Segal and Michael D. Whinston, Antitrust in Innovative Industries, 97 American Economic Review, 1703-1730 (2007). 